\title{
Behaviour Management of the Contemporary Child in Paediatric Dentistry: An Overview of the Research
}

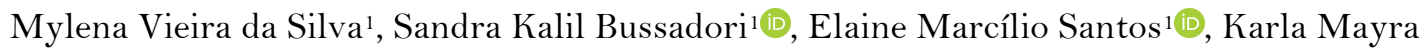 \\ Rezende ${ }^{1,2}$ (1)
}

'Departament of Paediatric Dentistry, Faculty of Dentistry, Metropolitan University of Santos, Santos, SP, Brazil.

${ }^{2}$ Departament of Paediatric Dentistry, Faculty of Dentistry, University of São Paulo, São Paulo, SP, Brazil.

Correspondence: Karla Mayra Rezende, Departamento de Odontopediatria, Faculdade de Odontologia da Universidade de São Paulo, Avenida Professor Lineu Prestes, 2227, Cidade Universitária, São Paulo, SP, Brazil. 05508-000. E-mail: karla.rezende@usp.br

Academic Editor: Catarina Ribeiro Barros de Alencar

Received: 22 September 2020 / Review: 26 December 2020 / Accepted: 30 January 2021

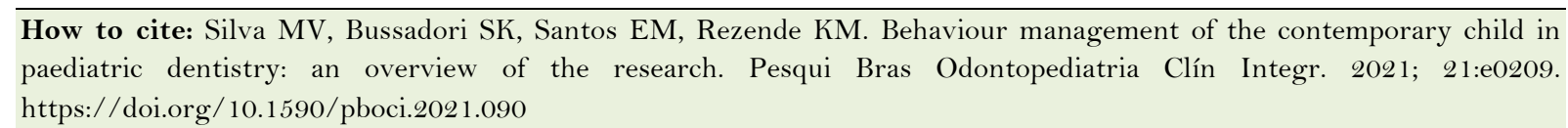

\begin{abstract}
Objective: To provide an overview of the most relevant studies on non-pharmacological behaviour management techniques for contemporary children, the so-called alpha generation, who undergo dental treatment. Material and Methods: A systematic search was performed on the Medline/PubMed and Google Scholar (grey literature) databases. The articles were read and data collected by two reviewers on an independent basis. Two reviewers collected data from the studies selected in tables structured by using the Rayyan QCRI software. The following data were extracted: year of study, child's age, child's gender, technique used. Results: A total of 322 articles were found, remaining only 17 after duplicates were removed and inclusion and exclusion criteria applied. The studies were conducted between 2010 and 2019 in Saudi Arabia, Greece, India, Brazil, USA, Italy, and Switzerland. The samples ranged from 15 to 306 children aged between 3 and 10 years old. The children attended the dental office for different reasons, ranging from simple prevention to endodontic treatment under local anaesthesia. Several behaviour modification methods are known to be used before and during a dental consultation. Conclusion: After reading the articles, we concluded that alpha generation children are inserted in a daily environment of modernization and that conventional non-pharmacological techniques using technology, such as audiovisual glasses, are more interesting and make children distracted and relaxed during dental treatment, thus minimizing their stress, anxiety and fear.
\end{abstract}

Keywords: Behavior and Behavior Mechanisms; Child Behavior; Fear; Anxiety. 


\section{Introduction}

Behaviour management in child dentistry is a science aimed at establishing a confidence relationship between patient and practitioner1. Some children are capable to cope well with potentially distressing situations, whereas others are more vulnerable to their own fears and impulses, thus making them more likely to react with emotional symptoms or non-cooperative behaviours [1]. The children's reactions to dental treatment are associated with age, temperament characteristics, maturity, personality, previous experiences, and common and dentist-related fears [2,3].

There is an increasing trend for parents to be present during the dental treatment, and this may be explained by some reasons such as the today's children are being seen and treated at a younger age; paediatric dentists adopt a more preventive approach to control oral diseases together with the parents, and the parents themselves want to be more present than in the past [4,5]. If, on the other hand, the presence of caretakers will not ensure good conduction of the treatment, it is important that they can observe it in a position in which the child cannot see them directly. This proximity between paediatric dentistry and children and their families helps the practitioner know the family's daily routine, who can analyse the child's behaviour and identify possible child abuse [6]. It is important to emphasise that in addition to physical characteristics, the abused child may have psychic disorders such as fear, anger, anxiety and distress, depression and isolation, compulsive lies, lack of confidence in adults, unjustified crying, reluctance to come back home, and poor school performance [7].

Interestingly, one can highlight that the behaviour of delaying the visit to the dentist for fear of pain or fear of dental care-related pain not only is harmful to health, but also can worsen the severity of a simple oral problem, which can demand specialised treatment over time and even invasive procedures (and consequently more possibility of feeling physical discomfort), in addition to increasing the treatment costs $[8,9]$.

Management strategies are conceptualised in the literature as a means to reduce the levels of stress, anxiety and fear in children during their dental treatment, being mainly divided into two categories. The first category consists of non-pharmacological behaviour management approaches such as tell-show-do (T-S-D) technique, distraction, role modelling and positive reinforcement [10,11]. The second one consists of pharmacological techniques [12].

Classification of individuals by generation has been widely used by companies for refining their discourse and solutions according to the behavioural characteristics of each generation. This classification is also very useful to understand how individuals behave according to their generations. There is a worldwide consensus regarding the classification of individuals into five generations: traditional or veteran generation, which consists of those born between 1925 and 1940, baby boomer generation (those born between 1946 and 1964), generation X (those born between 1965 and 1976), generation Y (those born between 1977 and 1994), generation $\mathrm{Z}$ (those born between 1995 and 2009), and finally the emergence of a new one, the so-called generation alpha.

Generation alpha are those children born from 2010 to 2025, and due to the current social context, they are focused on technology and can become digital influencers with peculiar experiences in this regard, despite their low age [13]. Therefore, this new generation has no credit yet and, even so, they are impacting the expenses of their generation Y parents [14].

The $21^{\text {st }}$-century children pose some challenges to the healthcare professional because their style of life has changed in the past decades [15]. They participate in various social life activities in a more engaged way and have a more technological experience, living more in a home and school environment and strongly 
driven by consumption. In this sense, they have knowledge and experiences no longer limited to family or school only, but which are processed through interactions with media and several other information sources $[16]$.

In this scenario, it is necessary that further studies be performed to understand the narrow relationship between new generation and techniques for adaptive behaviour management of the new child patient in the dental setting. Therefore, the objective of this study was to map studies on behaviour management techniques in the literature and assess whether they are suitable for these contemporaneous children.

\section{Material and Methods}

Study Design

This study was performed between July and September of 2020 , in which it was possible to determine the knowledge on systematically mapped evidence to identify key concepts, theories, evidence sources and research [17].

\section{Search Bases}

PubMed database and grey literature (Google Scholar) were searched, initially resulting in 100 articles. We also included guidelines recommending behaviour management techniques for children. The search strategy was performed for children younger than 10 years old according to definitions set by the World Health Organisation. Type of dental care and behaviour management techniques were considered for systematisation of information rather than for comparison, which can contribute to the practice and research by identifying gaps in the existing literature.

\section{Search Strategy}

The search strategy was the following:

((((children OR child OR pediatric OR paediatric OR infant OR toddler OR preschool AND $\left(\mathrm{y}_{-} 10[\right.$ Filter $\left.\left.]\right)\right)$ AND (pediatric dentistry OR paediatric dentistry OR dental care for dentistry AND $\left(\mathrm{y}_{-} 10[\right.$ Filter $\left.\left.\left.]\right)\right)\right)$ AND (Behavioral management approaches OR behavioral techniques OR Psychological/behavioral techniques OR Parent-Child Relations OR Child Behavior OR Dentist-Patient Relations AND (y_10[Filter $])))$ AND (cohort study OR randomized clinical study AND (y_10 [Filter $]))$ ) NOT (sedation OR autism OR pharmacology OR drugs OR therapeutics AND (y_10 [Filter $]$ )). Briefly, we can observe the most common terms shown in the word cloud regarding our search strategy (Figure 1).

\section{Selection and Eligibility Criteria}

The selection of the studies was performed on an independent basis. Agreements were solved by a third researcher expert on the theme. The inclusion criteria of the studies were the following: 1) focus on nonpharmacological behaviour management techniques in paediatric dentistry; 2) systematic reviews; prospective clinical assays (i.e., parallel groups or cross designs); observational studies (i.e., cohort, cross-sectional and case-control studies; series of clinical cases and case reports; guidelines); 3) publication from 2010 (beginning of the generation alpha era). The exclusion criteria were the following: 1) studies with children older than 10 years old (out of the generation alpha); 2) studies with special need patients; 3) studies using pharmacological techniques; and 4) studies conducted before 2010. Only studies fully available for reading were considered for analysis, whereas the partially available ones had their authors contacted. 


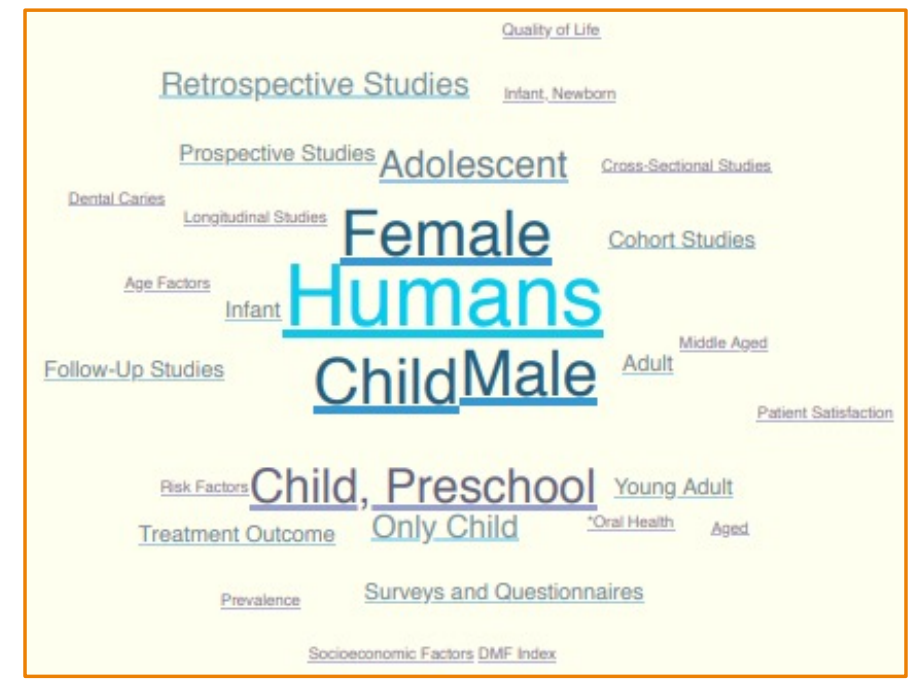

Figure 1. Word cloud.

Data Extraction Process

Two reviewers collected data from the studies selected in tables structured by using the Rayyan QCRI software. The following data were extracted: author, sample size, gender, child's age, objective and study design, technique used and results.

\section{Results}

Study Selection and Data Extraction

The flowchart of the study selection process is shown in Figure 2. The search on PubMed database yielded 313 articles, with two ones being excluded after reading the title and abstract. After exclusion of the remaining articles for not meeting the inclusion criteria, 17 ones were selected for data extraction. The search on grey literature was not relevant to our study because the resulting studies were not fully available or repeated on the other database, or the topics were out of scope.

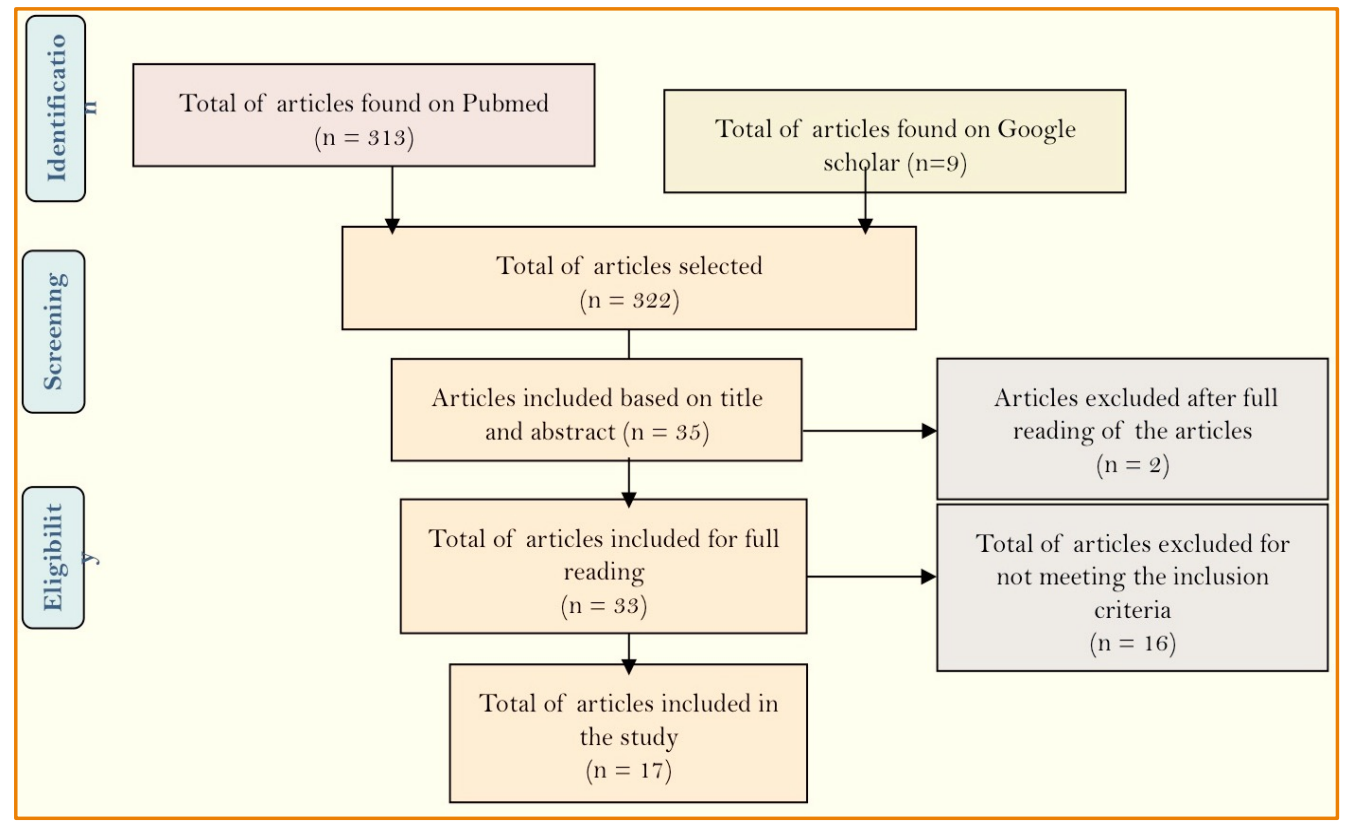

Figure 2. Flowchart. 
General Features of the Studies

The studies included were conducted between 2010 and 2019 in Saudi Arabia, Greece, India, Brazil, USA, Italy, and Switzerland, all written in English language [4,18-33]. The samples ranged from 15 [32] to 306 [29] children aged between 3 [4,30] and 10 [18,25] years old. The children attended the dental office for different reasons, ranging from simple prevention to endodontic treatment under local anaesthesia. Several behaviour modification methods are known to be used before and during the dental consultation. Moreover, of all articles analysed, the merit of each strategy used by each author relies on the fact that each type of technique aims to prepare the child and facilitate treatment adherence. The results found showed the importance of establishing clear communication with the child patient with adequate language in each situation since the generation alpha children differ from those born 30-40 years ago. Today's children go to school earlier and have access to technologies and media, which makes them more aware than a few years ago. We found that the studies included used the T-S-D technique together with audio-visual resources, which evolved over the years, in order to help manage the behaviour of these new children successfully during their experiences in the dental office (Table 1).

Table 1. Summary of characteristics extracted from the selected studies.

\begin{tabular}{|c|c|c|c|c|c|c|}
\hline Author & $\begin{array}{l}\text { Sample } \\
\text { Size }\end{array}$ & Gender & $\begin{array}{c}\text { Age } \\
\text { (Years) }\end{array}$ & Objective and Methods & Techniques Used & Results \\
\hline Boka et al. [4] & 61 & $\begin{array}{c}27 \text { Boys and } 31 \\
\text { Girls }\end{array}$ & $3-8$ & $\begin{array}{l}\text { To study the effectiveness of the presence of parents in behaviour } \\
\text { management during dental care. Children were randomly divided } \\
\text { into two groups. Use of conventional techniques and presence of } \\
\text { the parents. If the children behaved non-cooperatively, the parents } \\
\text { were asked to leave the dental office. }\end{array}$ & $\begin{array}{l}\text { Non-pharmacological } \\
\text { techniques and presence } \\
\text { of parents }\end{array}$ & $\begin{array}{l}\text { Presence of parents had } \\
\text { no interference with } \\
\text { dental care. }\end{array}$ \\
\hline Alnamankany [18] & 46 & $\begin{array}{l}23 \text { Boys and } 23 \\
\text { Girls }\end{array}$ & $6-10$ & $\begin{array}{l}\text { To assess the effect of video and role modelling on reducing } \\
\text { dental anxiety. Use of an anxiety scale prior to dental care. } \\
\text { Children were randomly divided into two groups: one group } \\
\text { watched the video and the other did not. }\end{array}$ & $\begin{array}{l}\text { Audio-visual distraction } \\
\text { and role modelling }\end{array}$ & $\begin{array}{l}\text { Children showed less } \\
\text { anxiety in the dental } \\
\text { office. }\end{array}$ \\
\hline Vishwakarma et al. [19] & 98 & $\begin{array}{l}57 \text { Boys and } 41 \\
\text { Girls }\end{array}$ & $5-7$ & $\begin{array}{l}\text { To assess the efficacy of the T-S-D technique with live role } \\
\text { modelling and compare the techniques during the dental visits. } \\
\text { Children were randomly divided into two groups. Phase I (first } \\
\text { visit): Group I - children were conditioned to receive several } \\
\text { dental procedures using live role modelling followed by oral } \\
\text { prophylaxis; Group II-- children were sent to the game room } \\
\text { where dental toys and customised dental tools were available } \\
\text { along with a cartoon character, followed by oral prophylaxis. } \\
\text { Phase II (second visit): after a 7-day interval, all children } \\
\text { underwent rotary restorative treatment. }\end{array}$ & $\begin{array}{l}\text { Role modelling, dental } \\
\text { toys and games, and T- } \\
\text { S-D technique }\end{array}$ & $\begin{array}{l}\text { T-S-D technique made } \\
\text { children more } \\
\text { comfortable and } \\
\text { confident during dental } \\
\text { care. }\end{array}$ \\
\hline Prado et al. [20] & - & - & - & $\begin{array}{l}\text { To determine whether distraction techniques reduce anxiety and } \\
\text { fear of the children and adolescents during dental treatment. } \\
\text { Controlled clinical studies on any type of distraction technique for }\end{array}$ & Systematic Review & $\begin{array}{l}\text { Distraction decreased } \\
\text { anxiety. }\end{array}$ \\
\hline
\end{tabular}
Controlled clinical studies on any type of distraction technique for managing dental anxiety and fear in children and adolescents were included. 
Liu et al. [21]

Serra Negra et al. [22]
To assess the efficacy of audio-visual distraction technique in the management of dental anxiety in children.

To analyse the effect of music on the child's anxiety during dental care. The study involved a cross, randomised, clinical trial with 34 children presenting two caries lesions on the occlusal surfaces of molars. Children were divided into two groups: $(\mathrm{G} 1)$ in the first session, dental restoration was performed with no music and in the second session with music. Clinical examination was performed in the first session and a modified atraumatic performed in the first session and a modified atraumatic
restorative treatment was performed in the second and third sessions. Mozart's $40^{\text {th }}$ symphony was played on earphones. Pulse rate was measured with a wrist oximeter. The Brazilian version of the Eysenck Personality Questionnaire - Junior (EPQ-L) was used to measure the child's personality.

to measure the child's personality.
To assess the efficacy of audio-visual techniques as a way of distraction to reduce anxiety during dental treatment. Cross, clinical trial in which 36 children received different dental procedures in two sessions according to the Frankl II and III scales, with and without audio-visual system. In the control visit, they were exposed to distraction, but conventional non-aversive behaviour management was used. Each dental visit was divided into four phases (explanation, anaesthesia injection, placement of rubber dam/use of tweezers and handpiece at high speed for 5 minutes). Pain in each phase of treatment was measured by using the Face, Legs, Activity, Cry, Consolability (FLACC) Scale. Comparison of the results regarding both interventions was statistically analysed by using Wilcoxon signed-rank test.

To assess the use of audio-visual tools as a way of reducing anxiety during dental care. This study was performed with children according to two age groups, that is, 4-6 and 6-8 years old in the first dental visit. The children of each age group were further divided into 3 subgroups: control, audio distraction and audio-visual distraction $(\mathrm{n}=10$ each). Each child of all subgroups attended three dental visits. The level of anxiety in each visit was assessed by using a combination of parameters for measurement of anxiety. Data were collected and tabulated for statistical analysis.

To assess the distraction technique by using audio-visual tools during dental restoration. Cross, randomised, clinical study. One restoration was performed by using audio-visual glasses and other using conventional behaviour management techniques. Subjective and objective pain was assessed by means of the revised Face Pain Scale (FPS-r) and the Face, Legs, Activity, Cry, Consolability (FLACC) scale.
Systematic Review

$$
\text { Music }
$$

distraction technique was less effective.

Reduced the anxiety.
Audio-visual glasses for distraction showing

animation chosen by the child
Audio-visual

voice control distraction; music and
Use of audio-visual glasses did not reduce anxiety.

\section{Audio-visual}

distraction
Audio-visual distraction with cartoon; T-S-D technique; voice tone; positive reinforcement.
Audio-visual technique did not replace conventional techniques. 
Fakhruddin et al. [26]
To assess the distraction technique with audio-visual tools to decrease anxiety in children undergoing anaesthesia. Clinical, cross, randomised study. Children were randomly divided into two groups and attended two sessions of pulp therapy at 1-week interval. In the session of treatment I, Group A used audio-visual glasses for distraction, whereas Group B watched a video on TV screen only. In the session of treatment II, Group A was submitted to pulp treatment with no audio-visual glasses for distraction, whereas Group B underwent pulp treatment with them. Each session involved pulp treatment of equivalent teeth on both sides of the mouth. In each session, the modified Child Dental Anxiety Scale (MCDAS) (f) was used to assess the level of anxiety before treatment. After the procedure, the children were instructed to rate their pain during treatment according to the Wong-Bakers Faces Pain Scale (WBs). Changes in the wris oximeter and heart rate were recorded every $10 \mathrm{~min}$.

To assess the use of TV showing a live dental procedure to the children as a way of reducing their anxiety during dental restoration. The study was a cross-sectional, randomised, controlled, clinical trial. Data were obtained during the two visits. The children were randomly divided into two groups. The restorative procedures were performed on one tooth per visit at a 1-week interval. The procedure was shown alive to the patient by using the video output linked to the TV screen. The levels of anxiety were assessed by using Venham Picture scale and writs oximeter.

To assess the effect of audio-visual distraction techniques on the was conducted with 28 children, who were randomly divided into two groups of 14 each. In Group 1: dental procedure was performed in the first visit while the patients were watching a performed in the first visit while the patients were watching a
cartoon, which was used as a visual distraction tool; in the second cartoon, which was used as a visual distraction tool; in the second
visit, the dental procedure was performed based on the T-S-D technique. Group 2: visual distraction was used in the second visit, whereas T-S-D technique in the first. Dental procedures were similar in both groups during the visits. Level of anxiety was determined by using the Venham Picture test and pulse rate in the beginning and end of each visit. Patient's behaviour was also measured by using the Frankl's behaviour rating scale (FBRS).

To assess the effect of reward on motivation after denta
treatment. Randomised, blinded study with systematic convenience sample of 396 children who had no previous dental experience and attended public dental services. Children were divided into control (G1) and experimental (G1) groups, with the latter receiving positive reinforcement with reward after denta
Audio-visual glasses for distraction and $\mathrm{TV}$

Set of techniques mad children less anxious.

Audio-visual distraction and T-S-D technique

Set of techniques made children less anxious.

Audio-visual distraction Audio-visual distraction reduced the anxiety.
T-S-D technique decreased anxiety along with frequent visits to the dental office. 
Hine et al. [30]

Tor

care. Projective test was used along with Venham Picture test.

To study the use of video to reduce anxiety during dental care of children. The video was created by a dentist using technology available and implemented in a routine clinical setting. The participants were randomly divided into two groups, one watching a brief video with a model and the other watching a control video a brief video with a model and the other watching a control video
before the routine dental care. All sessions were recorded in video and then independently evaluated by blinded observers. Behaviour data were recorded at a 15 -second interval and physical and vocal interruptions were included as well. Subjective measurements of cooperation were also performed by observers and dental professionals.

Al-Khotani et al. [31]

To assess the distraction technique with audio-visual tools to reduce anxiety in children undergoing dental treatment. Children were randomly divided into two groups: control group with no distraction (CTR) and distraction group (AV). Three visits for dental treatment were provided for each patient. Anxiety and cooperative behaviour were assessed by using the Facial Image scale (FIS), clinical anxiety scale, and modified Venham's clinical ratings of anxiety and cooperative behaviour scale (MVARS) Vital signs, blood pressure and heart rate were monitored.

To assess the distraction technique with audio-visual tools to reduce anxiety in children undergoing anaesthesia. Clinical, cross, randomised study. The children were randomly divided into two groups (Group A, $\mathrm{n}=7$; Group B, $\mathrm{n}=8$ ). The study involved three sessions at a 1-week interval. In session I, the T-S-D technique was used during prophylaxis while the participant watched a film (with sign language) with and without audio-visual glasses. In the final of session I, the smiling face score was used to assess anxiety. In sessions II and III, respectively, both groups underwent pulp treatment of teeth equivalent on both sides of the underwent pulp treatment of teeth equivalent on both sides of the
mouth with and without audio-visual glasses and vice-versa. After the procedure, the children were instructed to rate their pain during the treatment according to the Wong-Bakers Faces Pain Scale (WBs). Changes in the wrist oximeter and heart rate were recorded every $5 \mathrm{~min}$.

Guinot Jimeno et al. [33] $\quad 34 \quad$ Not Mentioned $\quad$ 6-8 To assess the parents' perception on the anxiety of their children by using audio-visual resources during dental treatment. This non-randomised cross study was performed in two sessions for restorative treatment. In the last session, the patient watched cartoon film.

Audio-visual distraction with video on dental care recorded by the dentist

Audio-visual distraction with cartoon

Audio-visual technique did not replace conventional techniques.

Audio-visual distraction and T-S-D technique

Audio-visual glasses made children less anxious.
Audio-visual glasses for distraction
Audio-visual glasses made children less anxious, but there was little interference of the parents. 


\section{Discussion}

Human development is the product of a continuous interaction between heredity and environment, with the latter having multiple influences on the individual's life, that is, from the intra-uterine stage to the integral and multidimensional development [34]. The rationale for the practice of paediatric dentistry is based on the ability to guide children in their experiences during the treatment. Behaviour management techniques using good communication establishes social and relationship directives. Indeed, symptoms such as anxiety, fear and stress may be present in children, which can have a negative impact on their quality of life and make dental care difficult or even cause the patient to flee $[9,15,35]$.

The generation alpha consists of children born after 2010 and of those who will be born until 2025 who, since very young, are inserted in a daily-life setting surrounded by technology. These children are more independent than the older generations during their full development as they have ability to adapt to new technologies [13]. This concept is important for adaptation of the current behaviour management techniques. For this reason, we searched on databases for studies addressing psychological control of the child's behaviour which were published from 2010. Among the limitations of the study, heterogeneity of the methodologies did not allow us to carry out a meta-analysis. The studies found according to the inclusion criteria were those recently published in the literature, that is, from 2014. The 3-4 year-olds are in the early childhood phase [4,28-30], a period in which the children are semi-independent as they have a certain self-control, logical reasoning and communicative development, all improving the communication with the practitioner. The learning process is quicker, countless skills are achieved and habits are formed in these generation alpha children.

The dental literature is rich in descriptions of potentially cooperative patients. Regarding the adverse reactions from children, they have been specifically labelled as uncontrollable, defiant, shy or tense-cooperative, all behaviours that demand special attention from the paediatric dentist. Therefore, it is essential that a psychological approach be used in the dental carer to establish a confidence relationship between patient and practitioner to mitigate stress, anxiety and fear in the former [36,37]. In the prevention and treatment of dental anxiety in children, the techniques found in the literature have shown good results as they are scientifically accepted and efective [38]. Among these techniques, one can cite the following: tell-show-do technique, introduced in 1959 by Adelson [39]; positive reinforcement technique, which consists in rewarding the child when the desired behaviour is achieved, thus motivating him or her for the next visits [37,40]; modelling technique, in which the child learns by observing [37]; voice control and distraction, whose goal is to change the child's focus and attention on an unpleasant moment or procedure [31]. However, we have been seeing children who have a fascination for technology. In 2010, the year marking the beginning of generation alpha, iPad ${ }^{\circledR}$ and Instagram were launched and "app" was the word of the year according to the American Dialect Society. These children believe that the technology's omnipresence in these years of formation leads to the increase in digital alphabetisation, as they access devices to play music, turn on the light or TV set by voice and learn through gamification, but on the other hand they have shorter attention spans and impaired social formation. The dental visit time for a child was not changed, lasting on average 30-40 minutes. In the studies published from 2010 to date, we observed that behaviour management techniques are related to the use of audio-visual glasses, which is a technologically updated method of distraction. According to Ram et al. [41], the use of audio-visual glasses was more interesting and effective for decreasing the anxiety and improving the cooperative behaviour of the child compared to relaxing techniques with TV set or music in the dental office. This may occur because distraction with audio-visual glasses make children be focused on the animation they 
are watching rather than on the noises in the dental office, such as those produced by high- and low-speed headpieces, photo-curing devices and X-ray.

Role modelling is another approach which was modernised by some authors. In this case, the surgeon dentist makes a video showing models using the T-S-D technique during the dental care and the child, still in the waiting room, watched it on the iPad ${ }^{\circledR}$ or smartphone and thus had an idea about the treatment. These approaches, when adapted to a computer screen and/or audio-visual glasses, can make the child less anxious during dental care [23,28,31,32]. Interestingly, the presence or absence of the parents did not influence the improvement of the child's behaviour during dental care [4,33]. However, it is important to say that all the studies selected described more than one way of managing the child's behaviour, including frequent visits for dental care. Therefore, the way how the paediatric dentist interacts with the child will influence the success of any dental treatment. Moreover, the use of conventional methods (e.g. T-S-D technique, positive reinforcement and music) together with technology (e.g., audio-visual glasses) provides a positive relationship between practitioner and child, as the anxiety of the former is reduced.

The more information on the children and their interaction with the environment where they live, the better for the practitioner to manage their behaviour accordingly and to have an adequate understanding of each patient. It is essential to know these strategies and update them to reduce the anxiety or negative behaviour of the paediatric patient before the dental treatment.

\section{Conclusion}

Today's children are born wired as they live surrounded by technology and are having a new view of the world, meaning that the use of interactive screens and audio-visual glasses is paramount. Therefore, it is essential to use these devices to distract and consequently relax the paediatric patient during the dental treatment.

It is important to say that the paediatric dentist should be prepared to improvise according to the need of each child and always updated about technological innovations, which can provide a more ludic approach without losing humanisation and effectiveness.

\section{Authors' Contributions}

\begin{tabular}{|c|c|c|}
\hline MVS & (iD) & Investigation and Writing - Original Draft. \\
\hline SKB & https://orcid.org/0000-0002-9853-1138 & Writing - Review and Editing and Visualization. \\
\hline EMS & https://orcid.org/0000-0003-1084-9940 & Writing - Review and Editing and Visualization. \\
\hline KMR & (iD) https://orcid.org/0000-0003-4340-0699 & $\begin{array}{l}\text { Conceptualization, Methodology, Formal Analysis, Investigation, Writing - Original Draft and } \\
\text { Writing - Review and Editing. }\end{array}$ \\
\hline
\end{tabular}

\section{Financial Support}

None.

\section{Conflict of Interest}

The authors declare no conflicts of interest.

\section{Data Availability}

The data used to support the findings of this study can be made available upon request to the corresponding author.

\section{References}


[1] Klingberg G, Broberg AG. Dental fear/anxiety and dental behaviour management problems in children and adolescents: a review of prevalence and concomitant psychological factors. Int J Paediatr Dent 2007; 17(6):391-406. https://doi.org/10.1111/j.1365-263X.2007.00872.x

[2] Folayan MO, Fatusi A. Effect of psychological management techniques on specific item score change during the management of dental fear in children. J Clin Pediatr Dent 2005; 29(4):335-40.

[3] Tsoi AK, Wilson S, Thikkurissy S. A study of the relationship of parenting styles, child temperament, and operatory behavior in healthy children. J Clin Pediatr Dent 2018; 42(4):273-8. https://doi.org/10.17796/1053-4628-42.4.6

[4] Boka V, Arapostathis K, Charitoudis G, Veerkamp J, van Loveren C, Kotsanos N. A study of parental presence/absence technique for child dental behaviour management. Eur Arch Paediatr Dent 2017; 18(6):405-9. https://doi.org/10.1007/s40368-017-0313-9

[5] Huebner CE, Milgrom P. Evaluation of a parent-designed programme to support tooth brushing of infants and young children. Int J Dent Hyg 2015; 13(1):65-73. https://doi.org/10.1111/idh.12100

[6] Kellogg N, American Academy of Pediatrics Committee on Child Abuse and Neglect. Oral and dental aspects of child abuse and neglect. Pediatrics 2005; 116(6):1565-8. https://doi.org/10.1542/peds.2005-2315

[7] Garrocho-Rangel A, Márquez-Preciado R, Olguín-Vivar AI, Ruiz-Rodríguez S, Pozos-Guillén A. Dentist attitudes and responsibilities concerning child sexual abuse. A review and a case report. J Clin Exp Dent 2015; 7(3):e428-34. https://doi.org/10.4317/jced.52301

[8] Luoto A, Lahti S, Nevanperä T, Tolvanen M, Locker D. Oral-health-related quality of life among children with and without dental fear. Int J Paediatr Dent 2009; 19(2):1 15-20. https://doi.org/10.1111/j.1365-263X.2008.00943.x

[9] Carrillo-Díaz M, Crego A, Armfield J, Romero M. The moderating role of dental expectancies on the relationship between cognitive vulnerability and dental fear in children and adolescents. Community Dent Oral Epidemiol 2013; 41(3):269-78. https://doi.org/10.1111/cdoe.12009

[10] Koticha P, Katge F, Shetty S, Patil DP. Effectiveness of virtual reality eyeglasses as a distraction aid to reduce anxiety among 6-10-year-old children undergoing dental extraction procedure. Int J Clin Pediatr Dent 2019; 12(4):297-302. https://doi.org/10.5005/jp-journals-10005-1640

[11] Abanto JA, Rezende KMPC, Bönecker M, Corrêa FNP, Corrêa MSNP. Non pharmacological approaches for the behavior management of children. Rev Estomatol Herediana 2010; 20(2):101-6.

[12] Asl Aminabadi N, Erfanparast L, Sohrabi A, Ghertasi Oskouei S, Naghili A. The impact of virtual reality distraction on pain and anxiety during dental treatment in 4-6 year-old children: a randomized controlled clinical trial. J Dent Res Dent Clin Dent Prospects 2012; 6(4):117-24. https://doi.org/10.5681/joddd.2012.025

[13] Carter C. The Complete Guide to Generation Alpha, The Children of Millennials. Avaliable from: https://www.forbes.com/sites/christinecarter/2016/12/21/the-complete-guide-to-generation-alpha-the-children-ofmillennials/?sh $=70 f f 44 d 53623$. [Acessed on September 10, 2020].

[14] Reis TA, Carneir CG, Bezerra FM, Oste G, Cremonezi G. Study on the alpha generation and the reflections of its behavior in the organizational environment. J Res Human Soc Sci 2018; 6(1):9-19.

[15] Long N. The changing nature of parenting in America. Pediatr Dent 2004; 26(2):12 1-4.

[16] Rusman NS, Ismail HN, Jaafar SMRS. Demand of preschool education by alpha generation on edutainment leisure in the city. Int J Built Env Sust 2019; 6(1-2):121-8. https://doi.org/10.11113/ijbes.v6.n1-2.391

[17] Tricco AC, Lillie E, Zarin W, et al. PRISMA Extension for Scoping Reviews (PRISMA-ScR): Checklist and Explanation. Ann Intern Med 2018; 169 (7):467-73. https://doi.org/10.7326/M18-0850

[18] Alnamankany A. Video modelling and dental anxiety in children. A randomised clinical trial. Eur J Paediatr Dent 2019; 20(3):242-6. https://doi.org/10.23804/ejpd.2019.20.03.14

[19] Vishwakarma AP, Bondarde PA, Patil SB, Dodamani AS, Vishwakarma PY, Mujawar SA. Effectiveness of two different behavioral modification techniques among 5-7-year-old children: A randomized controlled trial. J Indian Soc Pedod Prev Dent 2017; 35(2):143-9. https://doi.org/10.4103/JISPPD.JISPPD_257_16

[20] Prado IM, Carcavalli L, Abreu LG, Serra-Negra JM, Paiva SM, Martins CC. Use of distraction techniques for the management of anxiety and fear in paediatric dental practice: A systematic review of randomized controlled trials. Int J Paediatr Dent 2019; 29(5):650-68. https://doi.org/10.1111/ipd.12499

[21] Liu Y, Gu Z, Wang Y, Wu Q, Chen V, Xu X, Zhou X. Effect of audiovisual distraction on the management of dental anxiety in children: A systematic review. Int J Paediatr Dent 2019; 29(1):14-21. https://doi.org/10.1111/ipd.12430

[22] Serra-Negra JM, Abreu MH, Flores-Mendoza CE, Brant MO, Auad SM. The reassuring role of music associated with the personality traits of children during dental care: a randomized clinical trial. Eur Arch Paediatr Dent 2019; 20(5):441-9. https://doi.org/10.1007/s40368-019-00422-y

[23] Garrocho-Rangel A, Ibarra-Gutiérrez E, Rosales-Bérber M, Esquivel-Hernández R, Esparza-Villalpando V, PozosGuillén A. A video eyeglasses/earphones system as distracting method during dental treatment in children: A crossover randomised and controlled clinical trial. Eur J Paediatr Dent 2018; 19(1):74-9. https://doi.org/10.23804/ejpd.2018.19.01.14

[24] Kaur R, Jindal R, Dua R, Mahajan S, Sethi K, Garg S. Comparative evaluation of the effectiveness of audio and audiovisual distraction aids in the management of anxious pediatric dental patients. J Indian Soc Pedod Prev Dent 2015; 33(3):192-203. https://doi.org/10.4103/0970-4388.160357 
[25] Bagattoni S, D'Alessandro G, Sadotti A, Alkhamis N, Piana G. Effects of audiovisual distraction in children with special healthcare needs during dental restorations: a randomized crossover clinical trial. Int J Paediatr Dent 2018; 28(1):111-20. https://doi.org/10.1111/ipd.12304

[26] Fakhruddin KS, Hisham EB and Gorduysus MO. Effectiveness of audiovisual distraction eyewear and computerized delivery of anesthesia during pulp therapy of primary molars in phobic child patients. Eur J Dent 2015; 9(4):470-5. https://doi.org/10.4103/1305-7456.172637

[27] Sayed A, Ranna V, Padawe D, Takate V. Effect of the video output of the dental operating microscope on anxiety levels in a pediatric population during restorative procedures. J Indian Soc Pedod Prev Dent 2016; 34(1):60-4. https://doi.org/10.4103/0970-4388.175516

[28] Pinkham JR. Personality development. Managing behavior of the cooperative preschool child. Dent Clin North Am 1995; 39:771-87.

[29] Buchanan H, Niven N. Validation of a Facial Image Scale to assess child dental anxiety. Int J Paediatr Dent 2002; 12:47-52.

[30] Ghadimi S, Estaki Z, Rahbar P, Shamshiri AR. Effect of visual distraction on children's anxiety during dental treatment: a crossover randomized clinical trial. Eur Arch Paediatr Dent 2018; 19(4):239-44. https://doi.org/10.1007/s40368-018-0352-x

[31] Rank RCIC, Vilela JER, Rank MS, Ogawa WN, Imparato JCP. Effect of awards after dental care in children's motivation. Eur Arch Paediatr Dent 2019; 20(2):85-93. https://doi.org/10.1007/s40368-018-0394-0

[32] Hine JF, Hajek RT, Roberts HJ, Allen KD. Decreasing disruptive behaviour during routine dental visits: a video modelling intervention for young children. Int Dent J 2019; 69(4):265-72. https://doi.org/10.1111/idj.12457

[33] Bentoski JR, Boynton JR. Guiding the behavior of children in the dental setting. Opportunities for success. J Mich Dent Assoc 2011; 93(1):36-40.

[34] Roberts JF, Curzon ME, Koch G, Martens LC. Review: behaviour management techniques in paediatric dentistry. Eur Arch Paediatr Dent 2010; 11(4):166-74. https://doi.org/10.1007/BF03262738

[35] Davies EB, Buchanan H. An exploratory study investigating children's perceptions of dental behavioural management techniques. Int J Paediatr Dent 2013; 23(4):297-309. https://doi.org/10.1111/ipd.12007

[36] Adelson R, Goldfried MR. Modeling and the fearful child patient. ASDC J Dent Child 1970; 37(6):476.

[37] Vasconcelos C, Imparato JCP, Rezende KM. Motivation chart as a supporting tool in pediatric dentistry. RGO 2017; 65(3):276-81. https://doi.org/10.1590/1981-863720170002000153353

[38] Al-Khotani A, Bello LA, Christidis N. Effects of audiovisual distraction on children's behaviour during dental treatment: a randomized controlled clinical trial. Acta Odontol Scand 2016; 74(6):494-501. https://doi.org/10.1080/00016357.2016.1206211

[39] Ram D, Shapira J, Holan G, Magora F, Cohen S, Davidovich E. Audiovisual video eyeglass distraction during dental treatment in children. Quintessence Int 2010; 41(8):673-9.

[40] Fakhruddin KS, Gorduysus MO, El Batawi H. Effectiveness of behavioral modification techniques with visual distraction using intrasulcular local anesthesia in hearing disabled children during pulp therapy. Eur J Dent 2016; 10(4):551-5. https://doi.org/10.4103/1305-7456.195159

[41] Guinot Jimeno F, Mercadé Bellido M, Cuadros Fernández C, Lorente Rodríguez AI, Llopis Pérez J, Boj Quesada JR. Effect of audiovisual distraction on children's behaviour, anxiety and pain in the dental setting. Eur J Paediatr Dent 2014; 15(3):297-302. 